\title{
Management of Secondary Keratouveitis in a Wasp Sting Patient in a Jungle Region of Peru
}

This article was published in the following Dove Press journal:

International Medical Case Reports Journal

\section{Ana Luisa González $\mathbb{D}$ \\ Fermin Silva (DD \\ Robinson Barrientos (DD}

Department of Ophthalmology, Research Department Clinica La Luz, Lima, Peru
Correspondence: Ana Luisa González Department of Ophthalmology, Research Department Clinica La Luz, Av. Arequipa I I 48, Lima, Peru

Tel +5I 947273992

Email Dra.analuisagonzalez88@gmail.com
Abstract: Wasp stings are considered an ophthalmological emergency as they can be complicated when they occur near the eyelids or especially on the cornea. Due to type I hypersensitivity response, such as epithelial defect, corneal edema, loss of endothelial cells, anterior uveitis, optic neuritis and, therefore, permanent loss of vision due to anterior segment ischemia. It warns that the wasp stinger has a saw-shaped texture, contains toxins that inflame the area where it stings. Due to the immunological and toxic effects of the stinger and its venom infiltrates the cornea. We present the case of a 32-year-old man who presented keratouveitis secondary to a wasp sting in a region of the jungle of Peru. He was treated emergency with intensive steroid therapy to reduce the toxic effects. His follow-up up to 2 months was successful, leaving only a $1 \mathrm{~mm}$ central leukoma where the bite occurred, which did not impair his vision.

Keywords: hymenoptera, cornea, bee, wasp, sting, anterior chamber, acute keratouveitis

\section{Introduction}

Wasp stings are a nuisance for many as they cause burning, pain and inflammation in the affected area. These stings can become complicated when they occur near the eyelids or especially on the cornea. Due to type I hypersensitivity response, such as epithelial defect, corneal edema, loss of endothelial cells, anterior uveitis, optic neuritis, and therefore permanent vision loss due to anterior segment ischemia. ${ }^{1,2}$

Complications are according to the American Academy of Ophthalmology, which warns that the stinger, which has a saw-shaped texture, contains toxins that inflame the stung area. Due to immunological and toxic effects of the stinger and its venom is infiltrated in the cornea. Due to the infrequency of a sting, management is controversial. Furthermore, the structure of the stinger makes it difficult to remove it completely. ${ }^{3}$

The ideal is to treat patients with antibiotics and topical corticosteroids to prevent secondary infection and suppress inflammation, accompanied by cycloplegics to control pain and oral analgesics. 4

The stinger can be removed in the first step; however, it can be difficult to access and at the risk of leaving fragments. ${ }^{5}$

The novelty of our case report was the aggressive management with high doses of steroid that prevented the performance of surgical management. ${ }^{6}$

\section{Case Presentation}

A 32-year-old male patient from Iquitos-Peru, a farmer by trade, who attends the Clínica La Luz. The reported case complied with the Declaration of Helsinki. The 
ethics committee and the institutional review board of Clínica La Luz approved the reported case, to have the case details published. The patient gave his informed consent in writing for the details of the case and the images presented to be published.

The patient referred to the onset of the current disease, that being in a rural area, he had a wasp sting in his right eye, with increased palpebral volume, blurred vision and decreased visual acuity. Denying personal, family and ophthalmological history.

At best-corrected visual acuity (BCVA), right eye in hand movement, left eye 20/20, intraocular pressure (IOP) right eye $13 \mathrm{mmHg}$ and left eye $11 \mathrm{mmHg}$.

To biomicroscopy. Right eye presents moderate blepharospasm, $360^{\circ}$ mixed hyperemia, $360^{\circ}$ subconjunctival hemorrhage, subepithelial edema with deep stromal infiltration and endothelial edema, with fine keratic precipitates, where the presence of the stinger was not found, no seidel, with diffuse Descemet +++ membrane folds, anterior chamber formed (CAF) cellularity ++ , brown iris, clear crystalline (Figure 1). Left eye: without alterations. Eye fundus is performed: Right eye not assessable. Eye ultrasound ab mode: Right eye lens in situ, no vitreous lesions, retina applied. Specular microscopy right eye, not assessable endothelial cell count. It is diagnosed: Acute traumatic keratouveitis due to wasp sting.

Emergency therapeutic management is started, hydrocortisone $500 \mathrm{mg}$ intravenously once a day for 3 doses, prednisone in pyramidal scheme orally $1 \mathrm{mg} / \mathrm{kg}$ for 1 month and a half, loratadine $10 \mathrm{mg}$ orally every 24 hours for 10 days and topical solutions, prednisolone acetate $1 \%$ every 3 hours, hypertonic solution 5\% 5 times a day, tobramycin $0.3 \%$ /dexamethasone $0.1 \%$ every 6 hours,

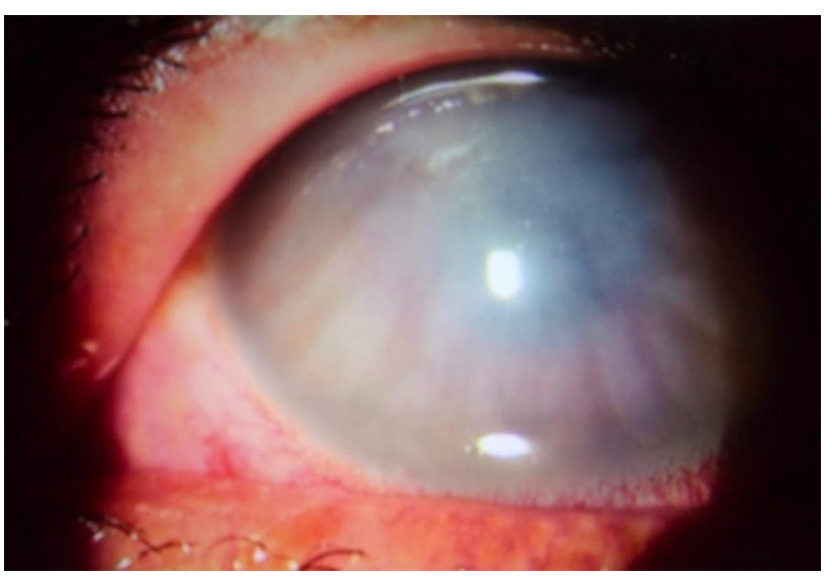

Figure I Subepithelial corneal edema, with deep stromal infiltration. brimonidine $0.2 \%$ /timolol $0.5 \%$ every 12 hours, tropicamide $1 \%$ every 8 hours, and control 7 days.

A week after control, he presented with improvement in symptoms and UCVA, Right eye 20/125 and distant BCVA 20/63, IOP $10 \mathrm{mmHg}$ taken with noncontact tonometer; Ocular Response Analyzer, Reichert, Depew, NY.

Biomicroscopy: mild blepharospasm, moderate mixed conjunctival injection, sub-epithelial corneal edema ++ with Descemet folds ++ , CAF, tyndall ++ , areas of iris hypotrophy in the lower sector, and clear lens.

The same management is continued and a control appointment is given after 15 days.

It is presented for control with BCVA 20/32 right eye, IOP 11. Biomicroscopy: clear conjunctiva, $2 \mathrm{~mm}$ central leukoma cornea with superficial epithelial defect, CAF, tyndall + , iris atrophy from 3 o'clock to 9 o'clock, clear crystalline. Loratadine and tobramycin with dexamethasone are suspended and maintained with prednisone at a dose of $5 \mathrm{mg}$ every 24 hours, and with reduction of topical solutions, prednisolone acetate $1 \%$ every 8 hours, hypertonic solution $5 \%$ every 8 hours, brimonidine $0.2 \%$ / timolol $0.5 \%$, tropicamide $1 \%$ every 8 hours, an appointment is made after a month and a half.

At his last control appointment, with BCVA 20/25 and IOP $10 \mathrm{mmHg}$ right eye. Biomicroscopy: corneal with central leukoma of $1 \mathrm{~mm}, \mathrm{CAF}$, non-tyndall, iris atrophy from 3 to 9 hours, clear lens (Figure 2).

Fundus was performed: normal both eyes. Specular microscopy with endothelial count reading from 1987 (Figure 3).

Treatment was suspended due to clinical improvement and only artificial tears were left, with the use of eye protection glasses.

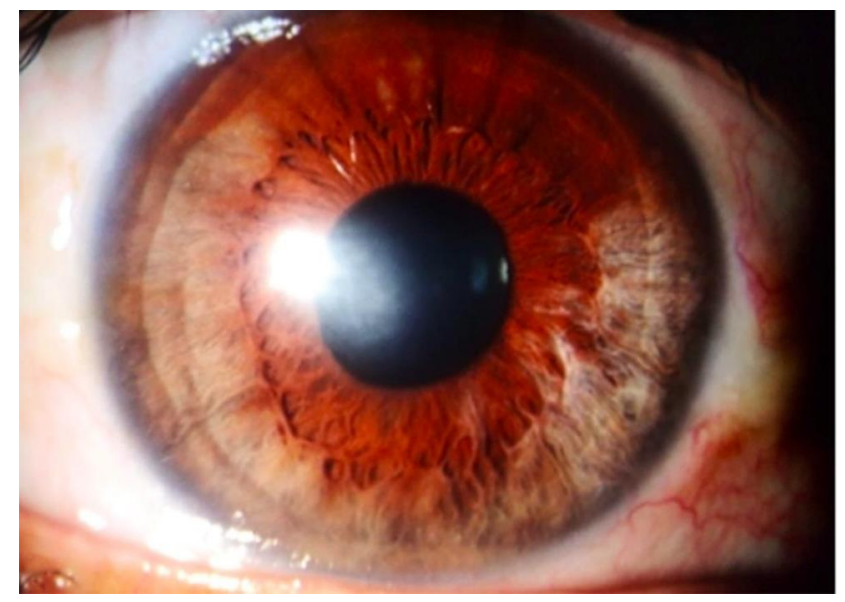

Figure 2 Central leukoma of Imm, with sectoral iris atrophy. 


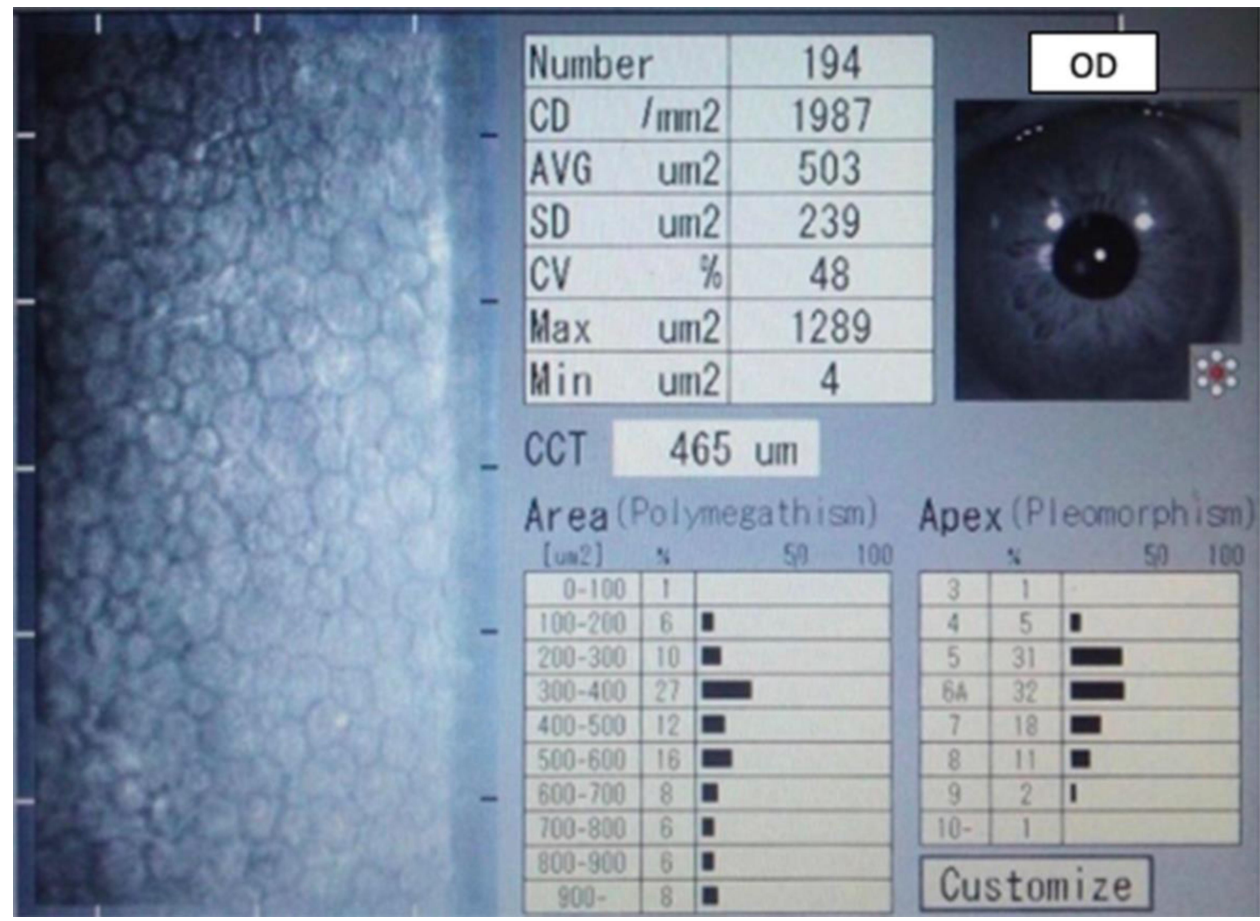

Figure 3 I It was possible to obtain a specular microscopy reading unlike the first day.

\section{Discussion}

In rural areas treated in our emergency department, insect bites to the eyes are a common event. Although an insect bite in other areas of the body can be painful, it is most common to cause relatively mild discomfort and, rarely, anaphylaxis. On the other hand, direct ocular involvement is a serious injury that can lead to serious and permanent complications. ${ }^{7,8}$

Hymenoptera venom-induced toxicity (bees, wasps, and ants) is caused by non-enzymatic polypeptide toxins (melittin, apamine, iminimine, mast cell granulator peptide) and enzymes (phospholipase A, phospholipase B, hyaluronidase, lipase, phosphatase acid, alkaline phosphatase, esterase and phosphodiesterase). ${ }^{7}$

Melittin causes heterochromia of the iris, induces the release of serotonin and histamine, as well as protein denaturation, which can lead to cataracts and delayed zonulolysis favoring lens subluxation. ${ }^{9}$

Apamine is a neurotoxin that can induce ophthalmoplegia and pupillary paralysis. Furthermore, the high molecular weight enzymes that enter the anterior chamber due to the bite are highly antigenic and responsible for the inflammation that results from the enzymatic hydrolysis of structural phospholipids. They are also responsible for inducing vasodilation and dissemination of the other toxic components. ${ }^{7,9}$
This aggression induces a reaction in the anterior chamber similar to a chemical burn. ${ }^{8}$

The best result according to Jain et al was obtained according to the speed of the therapeutic approach, when they were able to eliminate the insect bite early, with a $90 \%$ improvement in the symptoms and resolution of the keratouveitis. ${ }^{10}$

However, attempts to remove the sting manually prior to ophthalmological intervention induced an even greater inoculation of the venom due to the pressure exerted on the venom glands attached to the sting. But in cases of corneal infiltration accompanied by edema, the first step should be to remove the stinger from the tissue. Visscher ${ }^{11}$ suggested that it should be removed as soon as possible because the amount of venom injected correlates with the amount of time the stinger remains.

Due to the scarcity of the lesion, there are no established evidence-based guidelines for its management. It is generally accepted that the removal of the bee stinger is necessary in complicated cases with infiltration and corneal edema, especially if the stinger is deeply seated. ${ }^{6}$ However, it remains controversial whether the bee stinger should be removed and, if so, when and how it should be done. An attempt to eliminate often results in more inflammation due to the discharge of additional venom during handling. The topical steroids associated 
with the systemic ones decreased the inflammation of the cornea in this case, as was evident by the absence of associated infiltration. ${ }^{6}$ In some cases, an early irrigation of the anterior chamber with $10 \mathrm{~mL}$ of balanced saline solution, followed by the intracameral application of triamcinolone $(2 \mathrm{mg} / 0.2 \mathrm{~mL})$ to decrease the inflammatory reaction, as well as the amount of circulating toxins within the chamber anterior. ${ }^{12}$

The excellent functional and visual results in the reported patient were obtained with earlier and more aggressive treatment that led us to suggest that the management of corneal insect bites should include an early and aggressive therapeutic approach, in order to eliminate stings in case of being present and performing an irrigation of the anterior chamber with balanced saline solution if the affectation is very severe; however, each case must be individualized since this particular patient evolved satisfactorily and did not merit any additional surgical procedure to control the inflammation ocular.

The treatment includes topical corticosteroids and antibiotics. These patients require frequent and continuous follow-up due to the risk of late complications including persistent endothelial loss, anterior segment ischemia, cataracts, and glaucoma. ${ }^{7}$

Corneal transparency in the case described in this report was achieved approximately 4 to 8 weeks after the start of intensive anti-inflammatory treatment. ${ }^{5}$

A meeting was held with the cornea and uvea department about the case, in which the conclusion was reached that surgical treatment was not performed, because the patient did not present associated systemic diseases that further compromised the risk of visual loss, for what the treatment was only medical.

\section{Acknowledgments}

The authors thank the patient for his acceptance with the informed consent, to carry out the realization of this case.

\section{Disclosure}

The authors report no conflicts of interest in this work.

\section{References}

1. Lin P-H, Wang N-K, Hwang Y-S, Ma DH-K, Yeh L-K. Bee sting of the cornea and conjunctiva: management and outcomes. Cornea. 2011;30(4):392-394. doi:10.1097/ICO.0b013e3181f234a6

2. Gürlü VP, Erda N. Corneal bee sting-induced endothelial changes. Cornea. 2006;25(8):981-983. doi:10.1097/01.ico.0000226364.57172.72

3. American Academy of Ophthalmology. How to Treat a Bee Sting Near the Eye. May 20, 2020. Available from: https://www.aao.org/salud-ocu lar/consejos/how-to-treat-bee-sting-near-eye. Accessed October 24, 2020.

4. Muto T, Machida S. Wasp sting of the cornea. Int Med Case Rep J. 2018;11:283-286. doi:10.2147/IMCRJ.S178794

5. Nowroozzadeh MH, Hamid A, Bolkheir A, Shirvani M, Maalhagh M. Corneal wasp sting: a case report and review of literature. J Curr Ophthalmol. 2019;31(1):95-97. doi:10.1016/j.joco.2018.02.007

6. Vélez M, Mannis MJ, Ortega JG, Tobón CA. Corneal hymenoptera stings: a new therapeutic approach. Am J Ophthalmol. 2012;11 (4):117-120. doi:10.15324/vpa.v11i4.31

7. Smith DG, Roberge RJ. Corneal bee sting with retained stinger. $J$ Emerg Med. 2001;20(2):125-128. doi:10.1016/s0736-4679(00) 00298-5

8. Wong BWC, Lai JSM, Law RWK, Lam DSC. In vivo confocal microscopy of corneal insect foreign body. Cornea. 2003;22 (1):56-58. doi:10.1097/00003226-200301000-00013

9. Schmidt JO, Blum MS, Overal WL. Comparative enzymology of venoms from stinging hymenoptera. Toxicon off $J$ Int Soc Toxinology. 1986;24(9):907-921. doi:10.1016/0041-0101(86)90091-7

10. Jain V, Shome D, Natarajan S. Corneal bee sting misdiagnosed as viral keratitis. Cornea. 2007;26(10):1277-1278. doi:10.1097/ ICO.0b013e31814b8bae

11. Visscher PK, Vetter RS, Camazine S. Removing bee stings. Lancet Lond Engl. 1996;348(9023):301-302. doi:10.1016/s0140-6736(96) 01367-0

12. Nakatani Y, Nishimura A, Sugiyama K. Successful treatment of corneal wasp sting-induced panuveitis with vitrectomy. J Ophthalmic Inflamm Infect. 2013;3(1):18. doi:10.1186/1869-57603-18

\section{Publish your work in this journal}

The International Medical Case Reports Journal is an international, peer-reviewed open-access journal publishing original case reports from all medical specialties. Previously unpublished medical posters are also accepted relating to any area of clinical or preclinical science. Submissions should not normally exceed 2,000 words or 4 published pages including figures, diagrams and references. The manuscript management system is completely online and includes a very quick and fair peer-review system, which is all easy to use. Visit http://www.dovepress.com/testimonials.php to read real quotes from published authors 